\title{
Position Paper on the Necessity for Inpatient Primary Treatment of Breast Cancer
}

\section{Positionspapier zur Notwendigkeit stationärer Primärbehandlung des Mammakarzinoms}

Author

Affiliation

\section{T. Beck}

Klinik für Gynäkologie und Geburtshilfe, RoMed Klinikum Rosenheim, Rosenheim
Deutschsprachige Zusatzinformationen online abrufbar unter: www.thieme-connect.de/ ejournals/toc/gebfra
Bibliography

DOI http://dx.doi.org/

$10.1055 / \mathrm{s}-0033-1350949$

Geburtsh Frauenheilk 2013; 73 :

1005-1006 @ Georg Thieme

Verlag KG Stuttgart · New York . ISSN 0016-5751

\section{Correspondence}

Prof. Dr. Thomas Beck

Klinik für Gynäkologie

und Geburtshilfe

RoMed Klinikum Rosenheim

Pettenkoferstraße 10

83022 Rosenheim

thomas.beck@ro-med.de
This text was compiled in collaboration with representatives from the following professional associations and study groups:

$\nabla$

Prof. Dr. Thomas Dimpfl

President of the German Society for Gynaecology and Obstetrics

[Deutsche Gesellschaft für Gynäkologie und Geburtshilfe] (DGGG)

Kassel

Prof. Dr. Diethelm Wallwiener

German Society for Senology

[Deutsche Gesellschaft für Senologie] (DGS)

Tübingen

Prof. Dr. Matthias W. Beckmann

Guidelines Officer of the DGGG

Erlangen

Prof. Dr. Anton Scharl

Breast Commission of the

Gynaecological Oncology Study Group

[Arbeitsgemeinschaft Gynäkologische

Onkologie - Kommission Mamma] (AGO)

Amberg

\section{Prof. Dr. Andree Faridi}

Work Group for Aesthetic, Plastic and

Reconstructive Surgery in Gynaecology

[Arbeitsgemeinschaft für ästhetische, plastische und wiederherstellende Operationsverfahren in der Gynäkologie] (AWOgyn)

Berlin

\section{Dr. Gerhard Bartzke}

German Federal Association of Senior Consultants for Gynaecology and Obstetrics [Bundesarbeitsgemeinschaft leitender Ärztinnen und Ärzte

in der Frauenheilkunde und Geburtshilfe] (BLFG) Rottweil

\section{Hilde Schulte}

Honorary chairwoman of the Women's Self-help after Cancer [Frauenselbsthilfe nach Krebs] Bonn

Prof. Dr. Thomas Beck

Spokesman for the Work Group of Certified Breast Centres

[Arbeitsgemeinschaft zertifizierter Brustzentren] Rosenheim

An initial diagnosis of breast cancer will precipitate an acute crisis situation for the affected patient. The patient must cope with her uncertainties, feelings of despair and fears for the future. She will constantly be beset by worries about her own health, her family, her work and career, fears about potential pain, suffering and disability, but she will also hope to be cured.

At present, the multimodal treatment of breast cancer offers better chances of recovery than ever before. In a first step, the patient will attend a clinic in a certified breast centre where she will be informed, during the course of several lengthy and comprehensive informative conversations, about the treatment choices available and the type of treatment recommended in her individual case. The patient must make decisions with significant and far-reaching consequences, e.g. about her primary surgical treatment, neoadjuvant medical therapy, the necessity for primary sentinel lymph node biopsy, the choice of breast-conserving therapy or mastectomy with and without reconstruction at this point or at a later date. Radiation therapy is also part of therapy planning, and patients must also be informed about new treatments such as hypofractionated and intraoperative radiation. Providing information about the possibility of taking part in controlled trials is as important as weighing up the necessity for adju- 
vant chemotherapy based on modern prognostic factors such as tumour proteases and multigene signatures. And finally, the patient needs to be informed about the effectiveness of anti-hormone therapy in addition to or instead of systemic chemotherapy. Patients are rarely able to process all the information they receive from their physician immediately and completely.

On the other hand, these informative conversations can help to allay her fears step by step and allow her to carefully consider her decisions and talk them over with her family, friends and family physician. Crucial for the outcome of therapy in individual cases will be the extent to which the professional team of surgeons, psycho-oncologists, oncologists and radiotherapists can obtain the patient's trust when making the decision for the best treatment.

The improvements in the surgical treatment of breast cancer mean that operative procedures are increasingly breast-conserving and sparing. There can be no doubt that this facilitates postoperative healing and can shorten the time spent in hospital.

Active physical rehabilitation starts on the first postoperative day. Once the histo-pathological findings and the staging have been completed and the predictive factors have been assessed, the overall oncological situation of the individual patient is discussed in an interdisciplinary conference. A therapy concept is developed in the tumour conference with the collaboration of all disciplines involved; it takes account of current guidelines and the patient's individual situation (age, pre-existing medical conditions, therapy preferences, medication, family and work situation, etc.).

This interdisciplinary approach to diagnostics and therapy focuses not only on diagnostics, surgical therapy and nursing care but develops an overall oncological concept, which also includes taking account of psychosocial stresses. These tasks are currently the remit of the certified breast centres. The structures are only available in an inpatient setting and inpatient therapy is therefore necessary. For breast centres, a minimum stay of 4 days inpatient treatment is envisaged, it cannot be shortened without jeopardising the patient's chances of recovery.

The efforts by health insurance companies to treat early stage "small breast cancers requiring limited surgery" on an outpatient basis runs contrary to these quality specifications, ignores the requirements for overall care and directly contradicts the reality of care as described above.

Surgical procedures performed on an outpatient basis are therefore viewed extremely critically by the professional associations, in particular by the DGGG and patient organisations, because they do not comply with and adhere to these quality criteria and reduce the treatment of breast cancer to a brief surgical procedure.

On behalf of the above professional associations, work and study groups

Prof. Dr. Th. Beck

Rosenheim

Spokesman of the AG Z BZ 